\title{
Quechers Approach for the Determination of Seven Pesticide Residues in Brazilian Honey Samples Using GC- $\mu E C D$
}

Franz Zirena Vilca ${ }^{1}$, Maria Emilene Corrreia-Oliveira ${ }^{2}$, Rafael Marques Pereira Leal ${ }^{1}$, Sergio Henrique Monteiro ${ }^{1}$, Odimar Zanuzo Zanardi ${ }^{3}$, Luís Carlos Marchini ${ }^{2}$ and Valdermar Luiz Tornisielo ${ }^{1}$

1. Center of Nuclear Energy in Agriculture CENA, University of Sao Paulo, Av. Centenario 303 CEP 13400-970, P.O. Box 96, Piracicaba, Sao Paulo, Brazil

2. Useful Insects Laboratory, Department of Entomology and Acarology, "Luiz de Queiroz" College of Agriculture, University of Sao Paulo, Av. Padua Dias 11 CEP 13418-900, P.O. Box 09, Piracicaba, Sao Paul, Brazil

3. Laboratory of Integrated Pest Management, Departament of Entomology and Acarology, "Luiz de Queiroz" College of Agriculture, University of Sao Paulo, Av. Padua Dias 11 CEP 13418-900, P.O. Box 9, Piracicaba, Sao Paul, Brazil

Received: January 10, 2012 / Published: March 20, 2012.

\begin{abstract}
Honey is an important food widely used by people around the world. It can contain agrochemical residues as a result of the use of these products in agriculture. QuEChERS method was used for the determination of seven pesticide residues (chlorothalonil, heptachlor, captan, $\alpha$-endosulfan, $\beta$-endosulfan, endosulfan sulfate and dieldrin) in 25 Brazilian honey samples from different regions. Extraction was carried out through the use of $1 \%$ acetic acid-ethyl acetate solvent with $\mathrm{MgSO}_{4}$ and $\mathrm{CH}_{3} \mathrm{COONa}$, followed by dSPE cleanup with PSA sorbent. The analyses were carried out with GC- $\mu$ ECD. The chromatographic signal showed good linearity with correlation coefficient $\geq 0.99$ and the LOQs for the pesticides studied varied between 0.007 to $0.05 \mathrm{mg} \mathrm{kg}^{-1}$. The method was validated using a blank sample of honey spiked at three fortification levels $\left(0.07,0.2\right.$ and $\left.0.4 \mathrm{mg} \mathrm{kg}^{-1}\right)$. The recoveries for the seven compounds ranged from $75 \%$ to $119 \%$, and relative standard deviations were $\leq 26 \%$. Five of the 25 honey samples analyzed contained pesticide residues, with a maximum concentration of $0.026 \mathrm{mg} \mathrm{kg}^{-1}$ for $\alpha$-endosulfan. From the five contaminated samples, four were from non-agricultural areas, which indicated environmental contamination at these sites. The QuEChERS approach was successfully employed for the GC- $\mu$ ECD analyses of the seven studied pesticides in honey samples.
\end{abstract}

Key words: Pollution, honey, beekeeping, QuEChERS, GC- $\mu$ ECD.

\section{Introduction}

Honey production and exportation are rapidly increasing in Brazil. The country is currently the eleventh producer and the fifth world exporter of honey products, and the total amount exported raised from 269 tons in 2000 to 21,000 tons in 2005 [1].

Honeybees exposed to contaminated sites may transfer pesticide residues to the honey, affecting in

Corresponding author: Franz Zirena Vilca, Ph.D., research fields: student in science applied ecology; work with pesticides residues in food and environmental samples. E-mail: franz-cena-usp@hotmail.com. consequence human health [2]. The determination of pesticide residues in honey and also in other bee products can be a useful tool to gain information about possible contamination sites in the surroundings of the colonies [3].

Although honey production is constantly increasing in Brazil, local investigations concerning the occurrence of pesticide residues in honey samples are largely unavailable. In one of the few published works Rissato et al. [4] monitored for six years the presence of four major groups of pesticides (total of 48 compounds from organohalogen, organophosphorous, pyrethroids 
and organonitrogenin groups) in honey samples from Bauru, state of Sao Paulo, Brazil. Five halogens (ranging from 2 to $27 \mu \mathrm{g} \mathrm{kg}^{-1}$ ), three organonitrogenin groups (ranging from 1 to $70 \mu \mathrm{g} \mathrm{kg}^{-1}$ ), two organophosphorous (ranging from 11 to $243 \mu \mathrm{g} \mathrm{kg}^{-1}$ ) and one pyrethroid (ranging from 21 to $92 \mu \mathrm{g} \mathrm{kg}^{-1}$ ) were detected. In another study, Pittella [5] evaluated the occurrence of 20 pesticide residues (organochlorines, organophosphates, carbamates and pyrethroids) in 46 honey samples from different Brazilian regions, using GC-MS for this purpose. Eight samples tested positive, but concentrations were in all cases low $\left(<11 \mu \mathrm{g} \mathrm{kg}^{-1}\right)$, and in general below the limits allowed by legislation. Dieldrin was found in one sample $\left(6.4 \mu \mathrm{g} \mathrm{kg}^{-1}\right)$, but concentration was also within the limits allowed for this compound $\left(10 \mu \mathrm{g} \mathrm{kg}^{-1}\right)$.

An efficient and robust method is needed to detect and quantify pesticide residues with a high accuracy and precision [6]. QuEChERS is the most widely used method to analyze the presence of pesticide residues in a wide variety of matrices. The method consists of two steps: liquid-liquid extraction followed by clean up step with dispersive solid phase extraction (dSPE). The biggest advantage of this method is its simplicity, been easily adjustable to different matrices [7]. Modern methods, with simplified steps of extraction and clean-up like the QuEChERS save time and use less solvent, crucial aspects for an efficient pesticide residues monitoring program [6].

Mullin et al. [8] successfully adapted this method for the analysis of 200 pesticides and toxic metabolites in wax, pollen, propels and honey samples from different regions of USA, using LC-MS/MS and GC-MS/MS. In their work, the $15 \mathrm{~g}$ of sample usually needed was reduced to $3 \mathrm{~g}$ for the gas chromatography analysis. Barakat et al. [9] published a method for the analysis of thirty six different pesticides in honey where an additional concentration step was employed in order to reduce the method detection limits. Wiest et al. [10] used the QuEChERS method for the determination of 80 pesticides in honey samples by
LC-MS/MS and GC-QTof, using commercial kits with different proportions of salts for sample extraction.

The aim of this work was to validate the QuEChERS method for the determination of seven pesticides (chlorothalonil, heptachlor, captan, $\alpha$-endosulfan, $\beta$-endosulfan, endosulfan sulfate and dieldrin) by GC- $\mu \mathrm{ECD}$ in honey samples, and to use the validated method to evaluate the occurrence of these residues in 25 honey samples obtained from different Brazilian regions.

\section{Materials and Methods}

\subsection{Reagents}

Pesticide standards (chlorothalonil, heptachlor, captan, $\alpha$-endosulfan, $\beta$-endosulfan, endosulfan sulfate and dieldrin), with more than $98.9 \%$ of purity were obtained from Dr. Ehrenstorfer (Augsburg, Germany) and ChemService (West Chester, PA, USA). Stock solutions were prepared in HPLC grade toluene and stored at $-18{ }^{\circ} \mathrm{C}$. Working standard mixtures were obtained with appropriate dilution from stock solutions before use. Ethyl acetate and toluene were of pesticide grade (J.T. Baker), and acetic acid P.A, sodium acetate $\left(\mathrm{CH}_{3} \mathrm{COONa}\right)$, anhydrous sulfate magnesium (MgSO4) (J.T. Baker) and PSA (Varian) were all suitable for residues analysis.

\subsection{Samples and Gas Chromatography Analysis}

A honey sample without pesticide residues was used as a blank for the method performance. A total of 25 honey samples, obtained from eight Brazilian states, were evaluated (Table 1).

For the detection and quantification of the pesticides evaluated, a gas chromatograph apparatus (Agilent, model 7890A), equipped with a micro electron-capture detector $(\mu \mathrm{ECD})$ was used. An Agilent HP-5 $(30 \mathrm{~m} \times 320 \mu \mathrm{m} \times 0.25 \mu \mathrm{m})$ column was used and the Agilent Technologies ChemStation software B.04.02 was used for instrument control and data acquisition. The temperature program applied and 
Table 1 Sample number, cities and Brazilian states were the honey samples were obtained from Africanized honeybee Apis mellifera $\mathrm{L}$..

\begin{tabular}{|c|c|c|c|}
\hline Sample number & City & State & Location \\
\hline MS1 & Cassilandia & Mato Grosso do Sul & $19^{\circ} 06^{\prime} \mathrm{S} 51^{\circ} 44^{\prime} \mathrm{W}$ \\
\hline $\mathrm{RO} 2$ & Rolim de Moura & Rondonia & $11^{\circ} 48^{\prime} \mathrm{S} 61^{\circ} 48^{\prime} \mathrm{W}$ \\
\hline $\mathrm{SC} 3$ & Bom Retiro & Santa Catarina & $27^{\circ} 47^{\prime} \mathrm{S} 49^{\circ} 29^{\prime} \mathrm{W}$ \\
\hline $\mathrm{SC} 4$ & Bocaina do Sul & Santa Catarina & $27^{\circ} 37^{\prime} \mathrm{S} 49^{\circ} 52^{\prime} \mathrm{W}$ \\
\hline MG5 & Ipatinga & Minas Gerais & $19^{\circ} 28^{\prime} \mathrm{S} 42^{\circ} 35^{\prime} \mathrm{W}$ \\
\hline MG6 & Guanhaes & Minas Gerais & $19^{\circ} 02^{\prime} \mathrm{S} 42^{\circ} 55^{\prime} \mathrm{W}$ \\
\hline MG7 & Antonio Dias & Minas Gerais & $19^{\circ} 39^{\prime} \mathrm{S} 42^{\circ} 52^{\prime} \mathrm{W}$ \\
\hline MG8 & Marlieia & Minas Gerais & $19^{\circ} 42^{\prime} \mathrm{S} 42^{\circ} 44^{\prime} \mathrm{W}$ \\
\hline MG9 & Barrao de Cocais & Minas Gerais & $19^{\circ} 56^{\prime} \mathrm{S} 43^{\circ} 30^{\prime} \mathrm{W}$ \\
\hline MG10 & Caratinga & Minas Gerais & $19^{\circ} 48^{\prime} \mathrm{S} 42^{\circ} 08^{\prime} \mathrm{W}$ \\
\hline MG11 & Mesquita & Minas Gerais & $19^{\circ} 13^{\prime} \mathrm{S} 42^{\circ} 37^{\prime} \mathrm{W}$ \\
\hline MG12 & Pingo D'agua & Minas Gerais & $19^{\circ} 45^{\prime} \mathrm{S} 42^{\circ} 26^{\prime} \mathrm{W}$ \\
\hline PR13 & Paranagua & Parana & $25^{\circ} 32^{\prime} \mathrm{S} 48^{\circ} 31^{\prime} \mathrm{W}$ \\
\hline PR14 & Ortigueira & Parana & $24^{\circ} 13^{\prime} \mathrm{S} 50^{\circ} 55^{\prime} \mathrm{W}$ \\
\hline PR15 & Assis Chateaubriand & Parana & $24^{\circ} 24^{\prime} \mathrm{S} 53^{\circ} 31^{\prime} \mathrm{W}$ \\
\hline PR16 & Bandeirantes & Parana & $23^{\circ} 06^{\prime} \mathrm{S} 50^{\circ} 27^{\prime} \mathrm{W}$ \\
\hline SP17 & Junqueiropolis & Sao Paulo & $21^{\circ} 30^{\prime} \mathrm{S} 51^{\circ} 27^{\prime} \mathrm{W}$ \\
\hline SP18 & Icem & Sao Paulo & $20^{\circ} 20^{\prime} \mathrm{S} 49^{\circ} 11^{\prime} \mathrm{W}$ \\
\hline SP19 & Campinas & Sao Paulo & $22^{\circ} 53^{\prime} \mathrm{S} 47^{\circ} 04^{\prime} \mathrm{W}$ \\
\hline BA20 & Feira de Santana & Bahia & $12^{\circ} 15^{\prime} \mathrm{S} 38^{\circ} 57^{\prime} \mathrm{W}$ \\
\hline BA21 & Salvador & Bahia & $12^{\circ} 58^{\prime} \mathrm{S} 38^{\circ} 30^{\prime} \mathrm{W}$ \\
\hline BA22 & Ribeira do Pombal & Bahia & $10^{\circ} 50^{\prime} \mathrm{S} 38^{\circ} 31^{\prime} \mathrm{W}$ \\
\hline BA23 & Vitoria da Conquista & Bahia & $14^{\circ} 50^{\prime} \mathrm{S} 40^{\circ} 50^{\prime} \mathrm{W}$ \\
\hline BA24 & Tucano & Bahia & $10^{\circ} 57^{\prime} \mathrm{S} 38^{\circ} 47^{\prime} \mathrm{W}$ \\
\hline SE25 & Japaratuba & Sergipe & $10^{\circ} 25^{\prime} \mathrm{S} 36^{\circ} 56^{\prime} \mathrm{W}$ \\
\hline
\end{tabular}

$\mu$ ECD conditions were as follows: $180{ }^{\circ} \mathrm{C}-230{ }^{\circ} \mathrm{C}$ at a rate of $10{ }^{\circ} \mathrm{C} \min ^{-1}, 230{ }^{\circ} \mathrm{C}$ held for $5 \mathrm{~min}$ and $230{ }^{\circ} \mathrm{C}-280{ }^{\circ} \mathrm{C}$ at a rate of $20^{\circ} \mathrm{C} \mathrm{min}{ }^{-1}$, held for $5 \mathrm{~min}$. Carrier gas $\left(\mathrm{N}_{2}\right)$ was kept at a constant flow rate of 40 $\mathrm{mL} \min ^{-1}$ and detector temperature was $300{ }^{\circ} \mathrm{C}$. Quantification was carried out using calibration curves obtained both with standards in toluene and standards in matrix extracts.

\subsection{Extraction}

$10 \mathrm{~g}$ of honey sample were placed into polypropylene tube $(50 \mathrm{~mL})$ of conical base and homogenized with $10 \mathrm{~mL}$ of high purity water. After, $15 \mathrm{~mL}$ of $1 \%$ acetic acid in ethyl acetate extraction solvent, also containing $6 \mathrm{~g}$ of $\mathrm{MgSO}_{4}$ and $1.5 \mathrm{~g}$ of $\mathrm{CH} 3 \mathrm{COONa}$ anhydrous were added to each tube and hand-shaken vigorously for $1 \mathrm{~min}$, and centrifuged at $5,000 \mathrm{rpm}$ for $5 \mathrm{~min}$. For the sample clean-up an aliquot of $1 \mathrm{~mL}$ of the supernatant was transferred to a $2 \mathrm{~mL}$ polypropylene tube containing $50 \mathrm{mg}$ of PSA and $150 \mathrm{mg}$ of $\mathrm{MgSO}_{4}$, hand-shaken vigorously for 30 seconds and centrifuged at 5,000 rpm for $5 \mathrm{~min}$. Finally, $500 \mu \mathrm{L}$ of this extract was put into $1.5 \mathrm{~mL}$ vial and completed with $500 \mu \mathrm{L}$ of ethyl acetate. After, $1 \mu \mathrm{L}$ of the sample was injected on the GC- $\mu E C D$ system in the pulsed splitless mode for the residues analysis.

\subsection{Recovery Study}

Recovery study was carried out by spiking $10 \mathrm{~g}$ of the homogenized honey sample (free of the evaluated pesticides) with working standard solutions of pesticides at three fortification levels: 0.07, 0.2 and $0.4 \mathrm{mg} \mathrm{kg}^{-1}$, being that the first level corresponded approximately to the LOQ of the method for each pesticide, with five replicates for each level. After sample fortification, solvent was evaporated to allow sample equilibration prior to extraction. Fig. 1 shows a representative chromatogram of the sample spiked with all the studied compounds. 


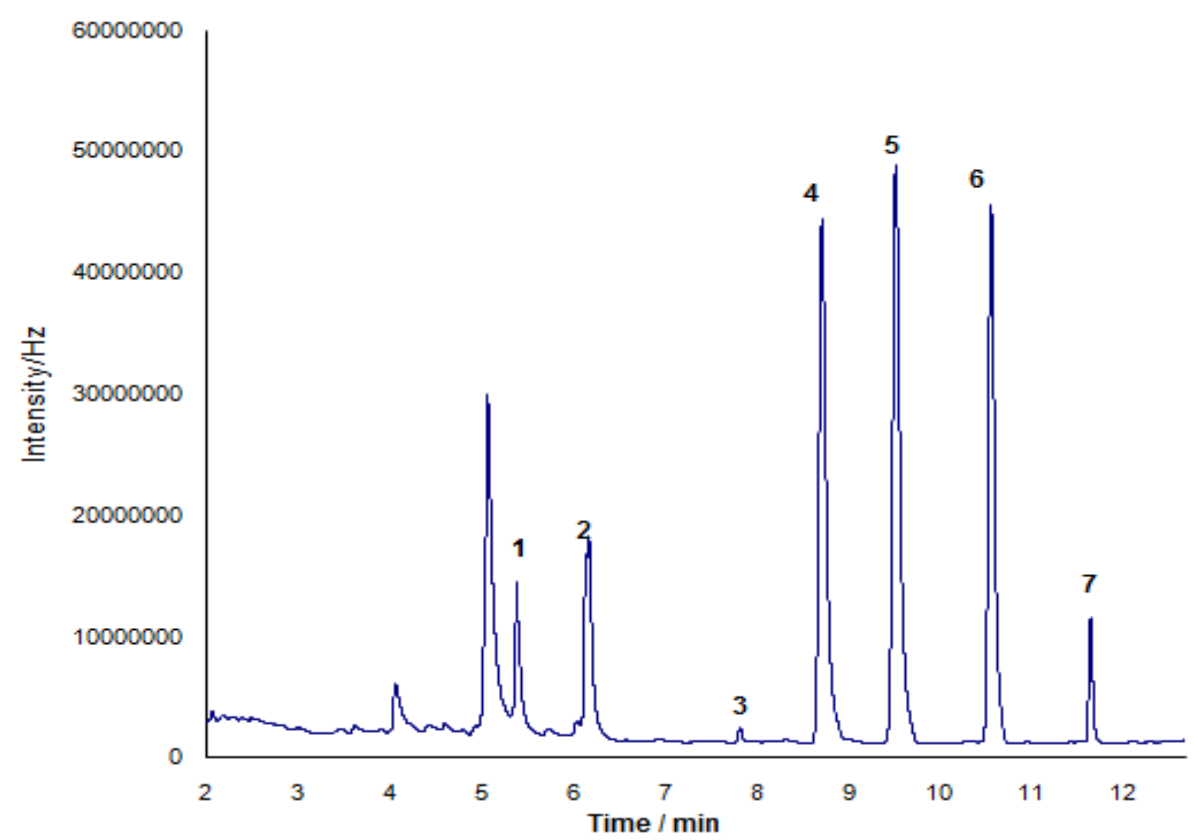

Fig. 1 Chromatogram of method showing the separation of seven compounds analyzed, (1) chlorothalonil, (2) heptachlor, (3) captan, (4) $\alpha$-endosulfan, (5) dieldrin, (6) $\beta$-endosulfam and (7) endosulfan sulfate, respectively.

\subsection{Preparation of the Calibration Curves}

A stock solution of each pesticide in toluene $\left(1 \mathrm{mg} \mathrm{mL}{ }^{-1}\right)$ was prepared. Stock solutions were used in the preparation of working standard solutions containing all pesticides at $100 \mu \mathrm{g} \mathrm{mL}^{-1}$. Two different types of calibration curves were prepared, one in the solvent and another one in the honey matrix, as follows: (1) seven working standard solutions at different concentrations $(0.001,0.01,0.05,0.1,0.15$, 0.25 and $0.5 \mu \mathrm{g} \mathrm{mL}^{-1}$ ) were prepared by serial dilution with toluene, corresponding to the solvent calibration curves (SC); (2) another seven working standard solutions at the same concentrations were prepared by serial dilution, using the honey matrix extract, corresponding to the matrix calibration curves (MC). This extract was obtained from the extraction of honey following the previously described analytical procedure. The matrix content in the standard solution was the same as in the spiked samples.

\section{Results and Discussion}

\subsection{Analysis}

In order to determine the matrix effect on the sensitivity of the detector (calibration curve), standard solutions containing a mixture of all the pesticides were prepared in solutions containing different proportions of solvent and matrix extract. There were no matrix effects and correlation coefficients $\left(r^{2}\right)$ were $\geq 0.99$. The retention times (Rt), limits of detection (LOD) and limits of quantification (LOQ) of the investigated pesticides are shown in Table 2. LOD and LOQ values and the sensitivity of the method were calculated according to INMETRO recommendations [11].

\subsection{Recovery Study}

Recovery experiments were conducted at three spiking levels $\left(0.07,0.2\right.$ and $\left.0.4 \mathrm{mg} \mathrm{kg}^{-1}\right)$. The first pesticide level was fortified near the LOQ level. The date in Table 3 represents the recoveries with RSDs obtained by a conventional standard calibration curve. The recovery values obtained were within the range of recommended values $(70 \%-120 \%$, witha relative standard deviations (RSDs) in general below $<20 \%$ ) [12]. Similar recoveries for $\alpha$-endosulfan, $\beta$-endosulfan and endosulfan sulfate were obtained in other works $[13,14]$. 


\subsection{Monitoring Study}

Five out of the 25 honey samples analyzed contained residues of the evaluated pesticides, and four of the seven molecules evaluated were detected (Table 4). From the detected compounds, three were insecticides/acaricides ( $\alpha$-endosulfan, $\beta$-endosulfan, endosulfan sulfate) and one was an insecticide (dieldrin). In Spain, a monitoring study found organochlorine residues in 89 of a total of 101 honey samples analyzed [15]. The compounds most often detected were: hexachlororocyclohexanes in 47 samples (up to $161 \mu \mathrm{g} \mathrm{kg}^{-1}$ ), lindane in 57 samples (up to $59 \mu \mathrm{g} \mathrm{kg}^{-1}$ ), heptachlor in 29 samples (up to $57 \mu \mathrm{g}$ $\mathrm{kg}^{-1}$ ), aldrin in 36 samples (up to $150 \mu \mathrm{g} \mathrm{kg}^{-1}$ ), op'DDT in seven samples (up to $12 \mu \mathrm{g} \mathrm{kg} \mathrm{kg}^{-1}$ ) and finally pp'DDT in 11 samples (up to $61 \mu \mathrm{g} \mathrm{kg}^{-1}$ ) [15].
The presence of these organochlorine residues in the honey samples was associated with the high solubility of these molecules in fat, causing their accumulation in the bees wax and thus also affecting the honeycombs [15].

From the five contaminated samples, only one (sample SE25, Table 4) was originated from an agricultural area (sugarcane). All the other samples were from non-agricultural areas, which indicated environmental contamination at these sites. This contamination was most probably due to the ingestion of contaminated food by the bees [14]. In Brazil, Rissato et al. [16] demonstrated the value of using the monitoring of pesticide residues in honey as an indicator of environmental contamination through a study conducted in Bauru, State of Sao Paulo.

Table 2 Rt (Retention times), LOD (limits of detection) and LOQ (limits of quantification) of the investigated pesticides.

\begin{tabular}{llll}
\hline \multirow{2}{*}{ Pesticides } & Rt in minutes & \multicolumn{2}{c}{ Limits $\left(\mathrm{mg} \mathrm{kg}^{-1}\right)$} \\
\cline { 3 - 4 } & & LOD & LOQ \\
\hline Chlorotalonil & 5.390 & 0.025 & 0.030 \\
Heptachlor & 6.149 & 0.032 & 0.033 \\
Captan & 7.829 & 0.029 & 0.035 \\
$\alpha$-endosulfan & 8.782 & 0.005 & 0.005 \\
Dieldrin & 9.533 & 0.008 & 0.008 \\
$\beta$-endosulfan & 10.572 & 0.007 & 0.007 \\
Endosulfan sulfate & 11.657 & 0.017 & 0.021 \\
\hline
\end{tabular}

Table 3 REC (Percentage recovery) and percentage of CV (Coefficient of Variation) of pesticides spiked at different concentrations $(n=5)$.

\begin{tabular}{|c|c|c|c|c|c|c|}
\hline \multirow{2}{*}{ Pesticides } & \multicolumn{2}{|c|}{$0.07 \mathrm{mg} \mathrm{kg}^{-1}$} & \multicolumn{2}{|c|}{$0.2 \mathrm{mg} \mathrm{kg}^{-1}$} & \multicolumn{2}{|c|}{$0.4 \mathrm{mg} \mathrm{kg}^{-1}$} \\
\hline & $\%$ REC & CV\% & $\%$ REC & $\mathrm{CV} \%$ & $\%$ REC & $\mathrm{CV} \%$ \\
\hline Heptachlor & $128.0 \pm 2.2$ & 6.00 & $125.0 \pm 4.8$ & 12.6 & $105.8 \pm 11.8$ & 26.4 \\
\hline Captan & $85.4 \pm 4.9$ & 13.0 & $85.18 \pm 5.50$ & 12.3 & $75.8 \pm 8.5$ & 19.1 \\
\hline$\alpha$-endosulfan & $90.2 \pm 4.3$ & 11.3 & $112.42 \pm 1.7$ & 4.00 & $117.9 \pm 5.4$ & 12.1 \\
\hline Dieldrin & $91.6 \pm 4.2$ & 11.2 & $113.53 \pm 1.7$ & 3.90 & $119.9 \pm 5.0$ & 11.1 \\
\hline$\beta$-endosulfan & $91.2 \pm 5.5$ & 14.5 & $109.96 \pm 1.6$ & 3.60 & $114.7 \pm 3.6$ & 8.10 \\
\hline Endosulfan sulfate & $95.7 \pm 7.4$ & 19.6 & $116.24 \pm 1.3$ & 2.90 & $118.5 \pm 3.3$ & 7.40 \\
\hline
\end{tabular}

Table 4 Pesticides residues in the Brazilian samples analyzed.

\begin{tabular}{llllll}
\hline \multirow{2}{*}{ Pesticides } & \multicolumn{5}{c}{ Pesticides residues in the samples $\left(\mathrm{mg} \mathrm{kg}^{-1}\right)$} \\
\cline { 2 - 5 } & MG20 & SC4 & SE25 & MG13 & SP23 \\
\hline$\alpha$-endosulfan & 0.026 & $<$ LOQ & 0.009 & 0.016 & 0.010 \\
Dieldrin & 0.011 & $<$ LOQ & $<$ LOQ & 0.012 & 0.010 \\
$\beta$-endosulfan & 0.014 & ND & $<$ LOQ & 0.013 & $<$ LOQ \\
Endosulfan sulfate & $<$ LOQ & ND & $<$ LOQ & ND & ND \\
\hline
\end{tabular}

$\mathrm{ND}=$ Not detected. 
Organochlorine residues were found during the monitored period (2003-2004), most notably malathion, with concentrations (up to $0.243 \mathrm{mg} \mathrm{kg}^{-1}$ ) higher than the other nine pesticide residues found (concentrations $\leq 0.092 \mathrm{mg} \mathrm{kg}^{-1}$ ) from a total of 48 investigated compounds. The occurrence of high concentrations of malathion in honey samples was linked to the application of this compound to control Aedes aegypti L. (Diptera: Culicidae), the mosquito that transmits dengue, a serious health problem at the region [4].

Contamination with endosulfan in this work was possibly related to the regular use of this compound in areas with intensive production of cotton, soybean and sugarcane, crops in which this molecule is commonly used.

\section{Conclusion}

In this work, a useful and fast method for the separation of seven pesticides was optimized using QuEChERS and GC- $\mu E C D$, and used for the determination of seven pesticide compounds in 25 samples of Brazilian honey from different regions. GC- $\mu E C D$ was an attractive alternative to determine these pesticides in honey, once the results indicated the method to be very sensitive (LOD of $0.005 \mathrm{mg} \mathrm{kg}^{-1}$ was the lowest value), also without matrix effect.

This method allows the use of honey as an indicator of pollution by pesticide residues, also enabling studies on the decomposition time of these pesticide residues in honey samples. For the installation of a honeybee colony with production purposes, it is necessary to investigate a radius of at least five kilometers for pesticides contamination, considering the dispersal ability of bees in their search for food. This is crucial in order to offer bee products that can be safely consumed by the population.

\section{Acknowledgments}

The authors express their gratitude to the Brazilian funding agencies CAPES, CNPq and FAPESP, which provided the financial resources used in the execution of this research.

\section{References}

[1] BCB-Brazilian Confederation of Beekeeping [online], http://www.brasilapicola.com.br/brasil-apicola.

[2] C. Blasco, M. Fernandez, A. Pena, C. Lino, M.I. Silveira, G. Font, et al., Assessment of pesticide residues in honey samples from Portugal and Spain, J. Agric. Food Chem. 51 (2003) 8132-8138.

[3] M. Gross, Pesticides linked to bee deaths, Curr. Biol. 18 (2008) R684.

[4] S.R. Rissato, M.S. Galhiane, F.R.N. Knoll, R.M.B. Andrade, M.V. Almeida, Método multirresíduo para monitoramento de contaminação ambiental de pesticidas na região de Bauru (SP) usando mel como bio-indicador, Quim. Nova 29 (2006) 950-955.

[5] C.M. Pittella, Determinação de resíduos de pesticidas em mel de abelhas (Apis sp.) por cromatografia de fase gasosa acoplada à espectrometria de massas, Dissertation, Universidade Federal de Minas Gerais-UFMG, Belo Horizonte, 2009, p. 119 , http://www.bibliotecadigital.ufmg.br/dspace/bitstream/18 43/SSLA-UZJQ7/1/ disserta o final_cd 1.pdf.

[6] M. Whelan, B. Kinsella, A. Furey, M. Moloney, H. Cantwell, S.J. Lehotay, et al., Determination of anthelmintic drug residues in milk using ultra high performance liquid chromatography-tandem mass spectrometry with rapid polarity switching, J. Chromatogr. A 1217 (2010) 4612-4622.

[7] M. Anastassiades, S.J. Lehotay, D. Stajnbaher, F.J. Schenck, Fast and easy multiresidue method employing acetonitrile extraction/partitioning and "dispersive solid-phase extraction" for the determination of pesticide residues in produce, J. AOAC Int. 86 (2003) 412-431.

[8] C.A. Mullin, M. Frazier, J.L. Frazier, S. Ashcraft, R.D. Simonds, R. van Engelsdorp, et al., High levels of miticides and agrochemicals in North American apiaries: Implications for honey bee health, PLoSOne 5 (2010) e9754.

[9] A.A. Barakat, H.M.A. Badawy, E. Salama, E. Attallah, G. Maatook, Simple and rapid method of analysis for determination of pesticide residues in honey using dispersive solid phase extraction and GC determination, J. Food Agric. Environ. 5 (2007) 97-100.

[10] L. Wiest, A. Buleté, B. Giroud, C. Fratta, S. Amic, O. Lambert, et al., Multi-residue analysis of 80 environmental contaminants in honeys, honeybees and pollens by one extraction procedure followed by liquid and gas chromatography coupled with mass spectrometric detection, J. Chromatogr. A 1218 (2011) 5743-5756.

[11] INMETRO-National Institute of Metrology, Standardization and industrial quality, orientação sobre validação de métodos de ensaios químicos, 
DOQ-CGCRE-008,

Brasil,

2010 ,

http://www.inmetro.gov.br/Sidoq/Arquivos/CGCRE/DO

Q/DOQ-CGCRE-8_03.pdf.

[12] European Commission 2010, Guidance document on pesticide residue analytical methods, SANCO/825/00 rev. 8.1, http://ec.europa.eu/food/plant/protection/resources/ guide_doc_825-00_rev7_en.pdf.

[13] D. Tsipi, M. Triantafyllou, A. Hiski, Determination of organochlorine pesticide residues in honey, applying solid phase extraction with RP-C18 material, Analyst 124 (1999) 473-475.

[14] Ö. Erdogrul, Levels of selected pesticides in honey samples from Kahramanmaraş, Turkey. Food Control 18 (2007) 866-871.

[15] M.A.F. Muiño, M.T. Sancho, J.S. Gándara, J.M.C. Vidal, J.F. Huidobro, J.S. Lozano, Organochlorine pesticide residues in Galician (NW Spain) honeys, Apidologie 26 (1995) 33-38.

[16] S.R. Rissato, M.S. Galhiane, M.V. Almeida, M. Gerenutti, M. Benhard, Multiresidue determination of pesticides in honey samples by gas chromatography-mass spectrometry and application in environmental contamination, Food Chem. 101 (2007) 1719-1726. 